Fixed Point Theory, 23(2022), No. 1, 331-350

DOI: $10.24193 /$ fpt-ro.2022.1.21

http://www.math.ubbcluj.ro/ nodeacj/sfptcj.html

\title{
EXISTENCE OF SOLUTION OF FUNCTIONAL INTEGRAL EQUATIONS BY MEASURE OF NONCOMPACTNESS AND SINC INTERPOLATION TO FIND SOLUTION
}

\author{
MOHSEN RABBANI*, REZA ARAB*, BIPAN HAZARIKA** AND NASSER AGHAZADEH*** \\ * Department of Mathematics, Sari Branch, Islamic Azad University, Sari, Iran \\ E-mail: mrabbani@iausari.ac.ir, \\ E-mail: mathreza.arab@iausari.ac.ir (Corresponding author) \\ ***Department of Mathematics, Gauhati University, Guwahati 781014, Assam, India \\ E-mail: bh_rgu@yahoo.co.in \\ ** Department of Mathematics, Azarbaijan Shahid Madani University, Tabriz, Iran \\ E-mail: aghazadeh@azaruniv.ac.ir
}

\begin{abstract}
In this article, we discuss the existence of solution for the functional integral equations in the Banach space $B C\left(\mathbb{R}^{+}\right)$of real-valued continuous and bounded functions, using the method associated with the technique of measure of noncompactness and generalized Darbo fixed point theorem. We provide an example to illustrate our results, and we make an iterative algorithm by the Sinc interpolation to find solution to the above problem with acceptable accuracy.

Key Words and Phrases: Functional integral equations, measure of noncompactness, operator type contraction, Sinc interpolation, iterative algorithm.
\end{abstract}

2020 Mathematics Subject Classification: 46B45, 46T99, 47H09, 47H10, 65D05.

\section{REFERENCES}

[1] R.P. Agarwal, M. Meehan, D. O'Regan, Fixed Point Theory and Applications, Cambridge University Press, 2004.

[2] A. Aghajani, R. Allahyari, M. Mursaleen, A generalization of Darbo's theorem with application to the solvability of systems of integral equations, J. Comput. Appl. Math, 260(2014), 68-77.

[3] A. Aghajani, J. Banaś, N. Sabzali, Some generalizations of Darbo fixed point theorem and applications, Bull. Belg. Math. Soc. Simon Stevin, 20(2013), no. 2, 345-358.

[4] D. Altun, A. Turkoglu, A fixed point theorem for mappings satisfying a general contractive condition of operator type, J. Comput. Anal. Appl, 9(2007), no. 1, 9-14.

[5] R. Arab, Some fixed point theorems in generalized Darbo fixed point theorem and the existence of solutions for system of integral equations, J. Korean Math. Soc., 52(2015), no. 1, 125-139.

[6] R. Arab, R. Allahyari, A.S. Haghighi, Existence of solutions of infinite systems of integral equations in two variables via measure of noncompactness, Appl. Math. Comput., 246(2014), 283-291.

[7] R. Arab, M. Rabbani, R. Mollapourasl, On solution of nonlinear integral equations with deviating argument based on fixed point technique, Appl. Comput. Math., 14(2015), no. 1, 38-49.

[8] E. Babolian, S. Abbasbandy, F. Fattahzadeh, A numerical method for solving a class of functional and two dimensional integral equations, Appl. Math. Comput., 198(2008), 35-43. 
[9] J. Banaś, Measures of noncompactness in the space of continuous tempered functions, Demonstratio Math., 14(1981), 127-133.

[10] J. Banaś, K. Goebel, Measures of Noncompactness in Banach Spaces, (Lecture Notes in Pure and Applied Mathematics), Dekker, New York, 60, 1980.

[11] J. Banaś, R. Rzepka, An application of a measure of noncompactness in the study of asymptotic stability, Appl. Math. Letters, 16(2003), 1-6.

[12] J. Banaś, R. Rzepka, On existence and asymptotic stability of solutions of a nonlinear integral equation, J. Math. Anal. Appl., 284(2003), 165-173.

[13] T.G. Bhaskar, V. Lakshmikantham, Fixed point theorems in partially ordered metric spaces and applications, Nonlinear Analysis, 65 (2006), 1379-1393.

[14] G. Darbo, Punti uniti in trasformazioni a codominio non compatto, Rend. Sem. Mat. Univ. Padova, 24(1955), 84-92.

[15] A. Das, B. Hazarika, P. Kumam, Some new generalization of Darbo's fixed point theorem and its application on integral equations, Mathematics, 7(2019), doi:10.3390/math7030214.

[16] B.C. Dhage, S.S. Bellale, Local asymptotic stability for nonlinear quadratic functional integral equations, Elec. J. Qualit. Theory Diff. Equ., 10(2008), 1-13.

[17] M. Geraghty, On contractive mappings, Proc. Amer. Math. Soc., 40(1973), 604-608.

[18] B. Hazarika, R. Arab, M. Mursaleen, Applications of measure of noncompactness and operator type contraction for existence of solution of functional integral equations, Complex Anal. \& Operator Theory, 13(2019), 3837-3851.

[19] B. Hazarika, E. Karapinar, R. Arab, M. Rabbani, Metric-like spaces to prove existence of solution for nonlinear quadratic integral equation and numerical method to solve it, J. Comput. Appl. Math., 328(2018), no. 15, 302-313.

[20] B. Hazarika, H.M. Srivastava, R. Arab, M. Rabbani, Application of simulation function and measure of noncompactness for solvability of nonlinear functional integral equations and introduction of an iteration algorithm to find solution, Appl. Math. Comput., 360(2019), no. 1, 131-146.

[21] X. Hu, J. Yan, The global attractivity and asymptotic stability of solution of a nonlinear integral equation, J. Math. Anal. Appl., 321(2006), 147-156.

[22] L. Liu, F. Guo, C. Wu, Y. Wu, Existence theorems of global solutions for nonlinear Volterra type integral equations in Banach spaces, J. Math. Anal. Appl., 309(2005), no. 2, 638-649.

[23] Z. Liu, S.M. Kang, Existence and asymptotic stability of solutions to functional integral equation, Taiwanese J. Math., 11(2007), 187-196.

[24] K. Maleknejad, I.N. Khalilsaraye, M. Alizadeh, On the solution of the integro-differential equation with an integral boundary condition, Numer. Algorithms, 65(2014), no. 2, 355-374.

[25] K. Maleknejad, M. Rabbani, N. Aghazadeh, M. Karami, A wavelet Petrov-Galerkin method for solving integro-differential equations, International Journal of Computer Mathematics, 86(2009), no. 9, 1572-1590.

[26] H.R. Marzban, H.R. Tabrizidooz, M. Razzaghi, A composite collocation method for the nonlinear mixed Volterra-Fredholm-Hammerstein integral equations, Commun. Nonlinear Sci. Numer. Simul., 16(2011), no. 3, 1186-1194.

[27] M. Rabbani, R. Arab, Extension of some theorems to find solution of nonlinear integral equation and homotopy perturbation method to solve it, Math. Sci., 11(2017), no. 2, 87-94.

[28] M. Rabbani, R. Arab, B. Hazarika, Solvability of nonlinear quadratic integral equation by using simulation type condensing operator and measure of noncompactness, Appl. Math. Comput., 349(2019), no. 15, 102-117.

[29] M. Rabbani, A. Gelayeri, Computation Adomian method for solving non-linear differential equation in the fluid dynamic, International J. Mechatronics, Electrical \& Computer Technology, $\mathbf{5}(2015), 2039-2043$.

[30] M. Rabbani, S.H. Kiasoltani, Discrete collocation method for solving Fredholm-Volterra integrodifferential equations, J. Operational Research and Its Applications (Applied Mathematics), 8(2011), 55-60.

[31] M. Rabbani, R. Mollapourasl, Sinc function in strip for Fredholm integral equation of the second kind, Mathematical Sciences, 2(2008), no. 2, 273-280. 
[32] M.T. Rashed, Numerical solution of functional differential, integral and integro-differential equations, Appl. Math. Comput., 156(2004), 485-492.

[33] F. Stenger, Numerical Methods Based on Sinc and Analytic Functions, Springer, New York, 1993.

[34] A.R. Vahidi, E. Babolian, Z. Azimzadeh, An improvement to the homotopy perturbation method for solving nonlinear Duffing's equations, Bull. Malaysian Math. Sci. Soc., 41(2018), no. 2, 1105-1117.

Received: May 16, 2020; Accepted: October 22, 2020. 
